\title{
Organisational culture, frontline supervisory engagement and accountability, as drivers of safety behaviour in a platinum mining organisation
}

\begin{tabular}{|c|c|}
\hline \multicolumn{2}{|c|}{$\begin{array}{l}\text { Authors: } \\
\text { Hayley Prinsloo }^{1} \text { (D) } \\
\text { Karl B. Hofmeyr }^{1} \text { (D) }\end{array}$} \\
\hline \multicolumn{2}{|c|}{$\begin{array}{l}\text { Affiliations: } \\
{ }^{1} \text { Gordon Institute of Business } \\
\text { Science, University of } \\
\text { Pretoria, Pretoria, } \\
\text { South Africa }\end{array}$} \\
\hline \multicolumn{2}{|c|}{$\begin{array}{l}\text { Corresponding author: } \\
\text { Karl Hofmeyr, } \\
\text { hofmeyrk@gibs.co.za }\end{array}$} \\
\hline \multicolumn{2}{|c|}{$\begin{array}{l}\text { Dates: } \\
\text { Received: } 29 \text { June } 2021 \\
\text { Accepted: } 30 \text { Oct. } 2021 \\
\text { Published: } 09 \text { Feb. } 2022\end{array}$} \\
\hline \multicolumn{2}{|c|}{$\begin{array}{l}\text { How to cite this article: } \\
\text { Prinsloo, H., \& Hofmeyr, } \\
\text { K.B. (2022). Organisational } \\
\text { culture, frontline } \\
\text { supervisory engagement } \\
\text { and accountability, as } \\
\text { drivers of safety behaviour } \\
\text { in a platinum mining } \\
\text { organisation. SA Journal } \\
\text { of Human Resource } \\
\text { Management/SA Tydskrif vir } \\
\text { Menslikehulpbronbestuur, } \\
\text { 20(0), a1705. https://doi. } \\
\text { org/10.4102/sajhrm. } \\
\text { v20i0.1705 }\end{array}$} \\
\hline \multicolumn{2}{|c|}{$\begin{array}{l}\text { Copyright: } \\
\text { (C) 2022. The Authors. } \\
\text { Licensee: AOSIS. This v } \\
\text { is licensed under the } \\
\text { Creative Commons } \\
\text { Attribution License. }\end{array}$} \\
\hline \multicolumn{2}{|l|}{ Read online: } \\
\hline 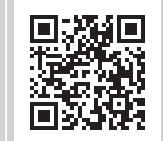 & $\begin{array}{l}\text { Scan this QR } \\
\text { code with your } \\
\text { smart phone or } \\
\text { mobile device } \\
\text { to read online. }\end{array}$ \\
\hline
\end{tabular}

Orientation: The mining industry plays a significant role in the South African economy. In 2020, the sector contributed R361.9 billion (7.9\%) to the total gross domestic product. With almost half a million employees reporting to work in the South African mining industry each day, a relentless commitment to safety and health compliance is required to manage the inherent risks and hazards associated with the sector.

Research purpose: The objectives of this study sought to contribute to the body of research on organisational culture, frontline supervisory engagement and accountability as levers for enhancing organisational performance and creating sustainable competitive advantage through resilient safety behaviour.

Research approach: Quantitative, confirmatory research methods were used to gain insight into the effect of organisational culture and safety climate on safety behaviour whilst examining the influencing effects of frontline supervisory engagement and accountability on safety behaviour in the process division of a single platinum mining organisation in South Africa.

Main findings: The key findings indicate that the tendency of a supervisor to hold herself and her team accountable is positively correlated with good safety behaviour and is the strongest predictor of safety behaviour when considering safety climate and supervisory engagement and supervisory accountability. Furthermore, safety climate was found to be a significant contributor to safety behaviour.

Practical implications: These results indicate that a significant influence exists between organisational culture, safety climate, supervisory accountability and safety behaviour. Supervisory engagement, although found to be positively correlated, was not a statistically significant predictor of safety behaviour.

Keywords: safety behaviour; organisational culture; frontline supervision; accountability; engagement; safety climate.

\section{Introduction}

\section{Orientation}

South Africa is known for its wealth of mineral resources, but industry leaders trying to create sustainable value and competitive advantage face several challenges because of today's rapidly changing and dynamic business environment (Cao \& Ramesh, 2008; Minerals Council South Africa, 2020). To remain competitive, many firms have been forced to prioritise operational efficiencies, which often results in leaner labour forces and additional productivity pressures on employees and organisations (Hakanen, Schaufeli, \& Ahola, 2008; Minerals Council South Africa, 2020). Within these constraints, firms are required to create and manage safe, secure and sustainable work environments (Cummings et al., 2010; Minerals Council South Africa, 2020).

The mining industry plays a significant role in the South African economy. In 2020, the sector contributed R361.9 billion (7.9\%) to the total gross domestic product and employed some 460000 people (Minerals Council South Africa, 2020). With almost half a million employees reporting to work in the South African mining industry each day, a relentless commitment to safety and health compliance is required to manage the inherent risks and hazards associated with the sector. In 2020, 58 fatalities were recorded in the sector, reflecting an increase of $18 \%$ from 2019 (Department of Mineral Resources and Energy, 2020). 
Previous research has revealed that frontline leaders have a direct influence on the safety behaviour of individuals and that their leadership significantly influences team safety performance (Fang, Wu, \& Wu, 2015; Lingard, Cooke, \& Blismas, 2012). Effective supervision sets and maintains high standards of performance and the physical aspects of the work environment and is critical to achieving and maintaining the desired safety culture (Delbridge \& Lowe, 1997; Weick, Sutcliffe, \& Obstfeld, 1997). Michael, Guo, Wiedenbach and Ray (2006) observed that because workers rely on frontline leaders to delegate tasks and to support and guide the execution of complex work in a dynamic environment, frontline leaders can have a direct and substantial impact on a team's safety behaviour and performance. However, it is important to understand what aspects of frontline leadership make it effective in driving safety behaviour and the successful management of risk.

\section{Research purpose and objectives}

This study set out to contribute to the body of research on organisational culture, frontline supervisory engagement and accountability, as levers in enhancing organisational performance through resilient safety behaviour. It would investigate the effect of organisational culture on safety behaviour whilst examining the mediating effects of frontline supervisory engagement and accountability on safety behaviour. Although these subjects have been comprehensively researched, they have not been thoroughly applied to frontline supervision and safety behaviour in the mining industry.

\section{Literature review}

The literature review is structured to give an oversight into the definitions for safety behaviour, safety climate and culture and organisational culture to provide context for the review. Thereafter, the importance of frontline supervision and the specific characteristics thereof are discussed before considering the antecedents of organisational culture, which may be used to leverage frontline supervisory skills in an effort to influence safety climate, behaviour and, ultimately, safety performance.

\section{Safety behaviour and climate}

Neal and Griffin (2006, p. 946) defined safety behaviour as 'the set of individual actions that meet or exceed particular role requirements in order to ensure workplace safety and reduced harm'. Furthermore, safety behaviour can be categorised into both participation and compliance behaviours (Neal \& Griffin, 2006; Pousette, Larsson, \& Törner, 2008; Yang, Zheng, Liu, Lu, \& Schaubroeck, 2019). Participatory safety behaviours include taking personal initiative to ensure personal safety and the safety of others, whereas safety compliance refers to adherence to procedures, instructions and rules designed to improve safety (Pousette et al., 2008; Tholén, Pousette, \& Törner, 2013; Yang et al., 2019). Despite there being a theoretical difference between safety participation and safety compliance, research on safety performance indicates that both are influenced by an employee's willingness to exert extra effort to behave safely, and this is in turn influenced by organisational culture (Neal \& Griffin, 2000; Pousette et al., 2008; Tholén et al., 2013).

Theoretical models and frameworks in safety literature do not adequately address why some individuals engage in more safety behaviours than others (Yang et al., 2019). It was thus suggested that the safety climate of an organisation can have an independent effect on individual safety behaviour. This would give organisations the ability to target specific interventions related to an individual's compliance with and participation in organisational safety practices (Neal \& Griffin, 2006).

\section{Organisational culture and safety climate}

Several studies have tried to identify the antecedents to safety behaviour in the mining industry. Stemn, Bofinger, Cliff and Hassall (2019) defined safety behaviour in the mining industry as a reflection of the perceptions, values, behaviours, attitudes and values concerning safety that are shared by employees. Lee and Harrison (2000) defined safety culture as the perception of risk, behaviours, values and beliefs that employees hold regarding their safety in the organisation. Organisational culture is defined as a collection of values, expectations and practices that advise and pre-empt the employees' behaviour (Al Mazrouei, Khalid, Davidson, \& Abdallah, 2019). This implies that the concept of safety behaviour cannot be researched in isolation, and consideration must be given to the organisational culture (Al Mazrouei et al., 2019).

Safety climate describes how individuals within an organisation perceive how safe the work environment is, and this is influenced by several factors, many of which are discussed as antecedents to organisational culture. These include supervisory support or management values such as how concerned management is with the well-being of their employees and the levels of care and respect shown in dealings with employees (Schneider, Yost, Kropp, Kind, \& Lam, 2018) and organisational practices and work attributes such as access to training, safety system quality, communication, the provision of equipment and employee involvement in workplace safety (Brown \& Leigh, 1996; Morrison, Upton, \& Cordery, 1997). Whereas a range of studies have established sound predictive relationships between these factors and safety-related incidents such as accidents (Brown \& Leigh, 1996; Zohar, 2010), few studies have established links between specific organisational culture factors and safety climate.

Supervisors play an important role in modelling safety behaviour and priorities during their interactions with frontline employees. Zohar and Luria (2003) proposed that supervisory support for appropriate safety behaviour is informed by organisational culture and that this manifests in organisation-wide safety behaviour. Furthermore, even 
though supervisors may have some discretion in how procedures are executed within their work groups, Zohar and Luria (2003) showed a positive relationship between organisational culture and work team safety climates. This suggests that a strong safety culture within an organisation should influence frontline supervisors to engage in behaviours that support workplace safety. In this light, this study hypothesises that a positive relationship exists between organisational practices, supervisory support, work attributes and safety climate:

- H1: Aggregate perceptions of organisational practices are a significant predictor of safety climate.

- H2: Aggregate perceptions of supervisory support are a significant predictor of safety climate.

- H3: Aggregate perceptions of work attributes that are meaningful and empowering are a significant predictor of safety climate.

\section{Frontline supervision and safety behaviour}

To address the issue of poor safety performance within the mining industry, academicians and practitioners have researched safety supervision as a possible way to improve the safety behaviour of employees. This emphasis on safety supervision is aligned with research that indicates that safety initiatives directed at supervisors are more effective at improving safety performance than initiatives directed at frontline employees (Zohar \& Luria, 2003) and research that finds that supervisors have a greater influence over the safety attitudes of employees than co-workers do (Dingsdan, Biggs, \& Sheahan, 2008).

Frontline supervisors have a direct impact on the safety behaviour of employees. Their leadership significantly influences team safety performance (Fang et al., 2015; Lingard et al., 2012). By virtue of their proximity to the workforce, frontline supervisors provide the first line of defence in managing risk, communicating organisational priorities and values and building relationships with individual team members (Delbridgel \& Lowe, 1997; Weick et al., 1997). Several studies have investigated the impact of frontline supervision on the safety behaviour and performance of employees. Hofmann and Morgeson (1999) found that the relationship between a supervisor and her team had an influence on their commitment to safety and safety-related communication. For example, a positive relationship between a supervisor and her team led to fewer workplace accidents.

\section{Supervisory accountability and safety compliance}

Accountability is a central component in all organisations, societies and communities. Without it, there would be no regard for consequences (Hall, Frink, \& Buckley, 2017; Hochwarter et al., 2007). Without accountability, coordinated undertakings would be difficult and organisations would find it difficult to operate efficiently (Frink \& Klimoski, 1998). Although accountability has clear benefits in relation to performance and efficiency, there are also negative consequences associated with heightened levels of accountability that contribute to job-induced tension, cognitive biases and job dissatisfaction (Hall et al., 2017; Hochwarter et al., 2007; Frink \& Klimoski, 1998).

Hierarchical accountability is common in high-risk industries where relationships are based on supervisors holding power over an employee because of their position or rank (McCall \& Pruchnicki, 2017). It exists when there is a contractual agreement between a superior and a subordinate, whereby the subordinates are expected to deliver on their accepted responsibilities and provide an account for their performance (Morrison, Upton \& Cordery, 1997).

Accountability is an important but complex construct that requires further research (Pearson \& Sutherland, 2017). Theory on the accountability of frontline supervisors and the consequences for safety performance in a mining environment has not been well understood. Given the work linking accountability and work performance, it is hypothesised that a frontline supervisor's ability to hold team members and herself accountable is an important factor when motivating employee safety compliance:

- H4: The ability of frontline supervisors to hold employees and themselves accountable has a positive influence on safety behaviour.

- H5: Aggregate perceptions of organisational practices are a significant predictor of supervisory accountability.

- H6: Aggregate perceptions of supervisory support are a significant predictor of supervisory accountability.

- H7: Aggregate perceptions of work attributes that are meaningful and empowering are a significant predictor of supervisory accountability.

\section{Safety engagement}

Organisational performance can be positively influenced by engaged employees and negatively impacted by actively disengaged employees (Hewitt, 2012). Muthuveloo, Basbous, Ping and Long (2013) suggested that employees who work in environments, which require physical work, such as mining, may be resentful or unhappy leading to disengagement at work. It is thus important for platinum mining organisations to understand the key drivers of employee engagement as this could affect and improve organisational performance.

Sahoo and Mishra (2012) found that when positively engaged, employees can form an emotional connection to an organisation, thus driving increased effort and individual performance. Subrahmanian (2014) went on to classify antecedents of employee engagement to include organisational practices, job satisfaction and attributes and supportive, collaborative teams and supervision. These characteristics were supported by Schaufeli, Martínez, Marques-Pinto, Salanova and Bakker (2002) who suggested a framework for measuring engagement based on work attributes, supervisory support and organisational practices such as a safe and supportive workplace. 


\section{Work attributes as an antecedent to engagement}

Work attributes are described as job-related characteristics that relate to the design or nature of the job, its challenges, required skill set, environment, safety and security, performance, remuneration and interpersonal relationships (Chen \& Chiu, 2016). Research completed by Fairlie (2011) found a strong association between meaningful job attributes and employee performance and that those work attributes predicted engagement levels. Farlie (2001) furthers this idea by showing that when an employee believes her job is fundamental, with a sense of meaning and purpose, it results in higher levels of engagement and interest in the work. Most platinum mining operations in South Africa are conventional mines, implying labour and heavy machinery intensive environments (Kunda, Frantz, \& Karachi, 2013). Historically, mineworkers from this industry have been clear about these unfavourable conditions, demanding decent living wages and benefits in compensation for their work environment. Employees tend to be more engaged when they are properly compensated for meaningful and challenging work (Schaufeli et al., 2002). Furthermore, when employees are encouraged to contribute to the decision-making process within their work environment, they are more likely to invest more time and effort into their work (Schaufeli et al., 2002).

\section{Supervisory support as an antecedent to employee engagement}

One of the key drivers of employee engagement suggested by Schaufeli et al. (2002) is autonomy and an environment in which an employee understands that he has choice and control over the decisions he makes and takes full responsibility for these actions. Employees who experience high levels of micromanagement exhibit active disengagement and an attitude of 'I just do what I'm told, and it is not my fault if anything goes wrong' (Cardus, 2013). In South Africa, mining organisations are still very hierarchical, authoritative and autocratic, and as such, it is likely that employees, particularly supervision and frontline workers, experience micromanagement during their daily routines.

\section{Organisational practices as an antecedent to engagement}

Schaufeli et al. (2002) defined factors such as work environment, team collaboration, leadership, interpersonal relationship with colleagues, career progression and training and development, organisational procedures and policies, compensation and safe and healthy workplaces as being key factors for employee engagement. Mine employees are typically exposed to difficult and uncomfortable working conditions, long hours, treacherous conditions often with radical unionised environments and with extreme pressure to perform safely and productively:

- H8: Aggregate frontline supervisor perceptions of engagement are significantly related to safety behaviour.

- H9: Aggregate frontline supervisor perceptions of organisational practices are a significant predictor of supervisory engagement.
- H10: Aggregate frontline supervisor perceptions of supervisory support are a significant predictor of supervisory engagement.

- H11: Aggregate frontline supervisor perceptions of work attributes that are meaningful and empowering are a significant predictor of supervisory engagement.

- H12: Aggregate frontline supervisor perceptions of work attributes that are meaningful and empowering are a significant predictor of supervisory engagement.

Although previous research has added greatly to the body of knowledge on the impact of leaders on safety behaviour, few studies have explored how safety behaviour is affected by work engagement and the felt accountability of frontline leaders. Furthermore, few studies have researched that organisational culture values have the greatest impact on work engagement and individual accountability.

\section{Research design}

The research was descriptive and exploratory in nature and was intended to identify the extent and nature of cause-and-effect relationships between supervisory work engagement, felt accountability and safety performance whilst providing a possible explanation for the quantified results by considering organisational culture and values (Saunders \& Lewis, 2012).

\section{Research approach}

This study was quantitative, allowing for both descriptive and confirmatory work to be carried out with the aim of making inferences about the findings related to a particular subject (Saunders \& Lewis, 2018). The study used a mono quantitative method as the data collected was in numerical form. Data were analysed using quantitative analysis techniques such as descriptive statistics, confirmatory factor analysis (CFA) for parametric testing and multiple linear regression analysis (Saunders \& Lewis, 2012).

\section{Research participants}

As the researchers had a list of all frontline supervisors in the organisation, probability sampling was applied. This sampling technique enabled the researchers to make statistical inferences about the population (Saunders \& Lewis, 2012). A simple random sample method was followed using the MS Excel random function, and a response rate of $80 \%$ was assumed. The required sample size, for a $95 \%$ confidence level with a 5\% margin for error, was 108 (Saunders \& Lewis, 2012). This is based on a total population of 157 frontline supervisors across the organisation's process division operations.

\section{Measuring instruments}

For this research, questionnaires from other research studies were used to measure the constructs identified. These questionnaires were found to produce accurate and reliable results when measuring safety behaviour and climate, 
engagement, accountability and organisational culture. In terms of ensuring validity and reliability, the researchers relied on previous research conducted in the same field of study to ensure validity and confirmed it using appropriate parametric testing. The researchers relied on Cronbach's alpha to establish the reliability of the instruments.

\section{Safety climate and safety behaviour}

Participants rated their safety behaviour using an established 12-item scale proposed by Neal and Griffin (2006) and used in Yang, Zheng, Liu, Lu and Schaubroeck (2019). The scale consists of four subscales measuring safety climate, safety motivation, safety compliance and safety participation. To assess the discriminant validity of these four dimensions, a CFA using the maximum likelihood estimation (MLE) method was considered and factors that were loaded incorrectly were removed. The discriminant validity between safety compliance and safety participation was not supported. This was consistent with the Yang et al. (2019) study, and safety behaviour was collapsed to consist only of participation and motivation.

\section{Supervisory work engagement}

Participants rated their engagement using the Utrecht work engagement scale as proposed by Schaufeli et al. (2002). The scale consists of three subscales measuring vigour, dedication and absorption. To assess the discriminant validity of these dimensions, a CFA using the MLE method was considered, and factors that were loaded incorrectly were removed. The discriminant validity of all factors was supported, consistent with results in the extensive literature.

\section{Supervisory accountability}

Participants rated their experience with accountability using the eight-item scale proposed by Hochwarter, Kacmar and Ferris (2003). The scale consists of two subscales measuring job accountability and perceived accountability. The MLE method was again considered, and the discriminant validity of both factors was supported.

\section{Organisational culture factors}

Participants rated factors of their organisational culture using the tested profile proposed in Schneider, Yost, Kropp, Kind and Lam's (2018) study of the organisational antecedents to workforce engagement. The scale consists of three subscales measuring organisational practices, supervisory support and work attributes. To assess the discriminant validity of these three dimensions, a CFA using the MLE method was considered. The discriminant validity of all factors was supported, consistent with the results in Schneider et al. (2018).

\section{Research procedure}

Data were collected through the distribution of surveys to identified frontline supervisors within the organisation. Two distribution channels were used. Where easy access to the employees was available, fieldworkers distributed printed copies of the questionnaires to identified employees and assisted with the accurate completion of the surveys. Where access to employees was inconvenient because of constraints of distance, web-based surveys were emailed to the identified respondents. The structured questionnaire was used as the single data collection tool for this study. If necessary and for quality control purposes, efforts were made to ensure individuals completing the surveys fully understood the questions being asked, as well as the nature of the responses available. The questionnaires were designed to be simple and contained minimal free text fields in an effort to avoid mistakes. Saunders and Lewis (2018) recommend that a sample of the recorded data must be first reviewed in an effort to establish whether there is a high rate of error. In the event of an unacceptable error rate, all forms would be reviewed. This process was followed after 25 electronic responses had been received prior to conducting the written surveys. The survey was in English, and an interpreter was available if required. Because data transfer may also result in input errors, outliers were double checked for incorrect inputs and duplication errors and free text was scrutinised. A total of 104 responses were collected, reflecting a response rate of $77 \%$. Of these 104 responses, 97\% were included in the analysis and a small number of responses were excluded because they were either incomplete or incorrect.

\section{Analysis}

The analysis approach was based on ranked data obtained from the measurement instruments using a Likert scale. These data were analysed using the EQS 6 for Windows and SPSS software. Descriptive statistics were used to explain the data collected, and inferential statistical methods were used to test the significance of differences or relationships between responses.

Cronbach's alpha was used to test for reliability in the research. Confirmatory factor analysis was used to confirm the underlying structure amongst the factors in the survey and to test the hypotheses for relationships and influences between the observed variables - such as survey scores or Likert scale ratings - and underlying variables or factors. Correlation and regression methods were used to analyse and quantify the extent and nature of relationships between the different variables (Barbars, 2015; Hochwarter et al., 2007; Schnieder et al., 2018).

The hypotheses for the study were specifically related to the nature and direction of the relationship between the constructs. Two variables were considered in this analysis. The correlation coefficient would give an indication of the direction of the relationship, positive or negative. The probability of these coefficients in the ANOVA was considered when deciding on the significance of the predictability. The hypothesis would be accepted as significant if it yielded a $p$-value of less than 0.05 . 


\section{Ethical considerations}

This research was approved by CUT, Free State, South Africa. Ethical clearance has been provided by the Faculty Research and Innovation Committee [03/05/17] in view of the CUT Research Ethics and Integrity Framework, 2016 with reference number [Management Sciences 0717].

\section{Results}

The participants in this research were 104 frontline supervisors within the processing division of a large platinum mining organisation in South Africa. Of these participants, $87.1 \%$ were men, $11.9 \%$ were women and $1 \%$ preferred not to say what their gender was. These statistics compare well with reports from 2018 and 2019, which found inclusion rates of between $11 \%$ and $12 \%$ for women in the platinum mining sector (Minerals Council South Africa, 2020).

In terms of age and education, $49.8 \%$ of respondents were older than 40 and $52 \%$ of respondents had completed primary or secondary schooling. The remaining $48 \%$ of respondents indicated that they had tertiary or postgraduate education. Of the 104 responses received, all participants indicated that they had supervised or currently were supervising a team of employees. Furthermore, $67 \%$ of respondents indicated that they had more than 10 years of supervisory experience.

Almost a quarter (22\%) of respondents indicated that they had been injured at their workplace and $58.3 \%$ of respondents stated that a member of a team who they supervised had been injured at work. Most (86\%) respondents indicated that they were the primary breadwinner in their families and $96.2 \%$ of respondents had between 1 and 15 dependents. Many respondents (61\%) indicated that they had between 1 and 4 dependents.

\section{Safety climate}

The first objective of the research was to address the relationship between organisational factors and safety climate. Although a range of studies have established sound predictive relationships between safety climate and safetyrelated incidents such as accidents (Brown \& Leigh, 1996; Zohar, 2010), few have established links between specific organisational factors and safety climate. It was proposed that factors such as organisational practices, supervisory support and work attributes within an organisation provide the context for the formation of specific safety perceptions and thus should predict safety climate.

The three independent variables of organisational practices, supervisory support and work attributes were considered as factors of organisational culture and were analysed in a model for variance. Based on the adjusted $r^{2}$-value, 37.3\% of the variance in safety climate could be attributed to organisational culture. Considering the range of other organisational culture factors not considered in this research, a $37.3 \%$ variance was considered significant and thus a strong factor that organisational leadership should consider leveraging to create a positive and resilient safety climate. This result confirms the findings of Wiegmann et al. (2004) and adds to the body of research required by Zohar (2010).

\section{Aggregate perceptions of organisational practices are a significant predictor of safety climate (H1)}

Hypothesis 1 aimed to establish whether perceptions of organisational practices could be used to predict the safety culture of an organisation. The analysis using multiple linear regression analysis between organisational practices (independent variable) and safety climate (dependent variable) illustrated a positive, moderately strong relationship, with a correlation coefficient of 0.527 across 103 participants (see Table 1). For the purposes of this research, examples of organisational practices included effective communication from senior leadership, transparent and fair recognition, compensation and opportunity for promotion, goal clarity and employee well-being. This result indicates that organisational practices that positively enhance perceptions of their organisation also positively influence the safety climate of the organisation. An analysis of variance indicated a significant correlation between organisational practices and safety

TABLE 1: Statistical tests applied to the research hypotheses.

\begin{tabular}{|c|c|c|}
\hline Hypothesis & $\begin{array}{l}\text { Multiple linear } \\
\text { regression }\end{array}$ & Analysis of variance \\
\hline Aggregate perceptions of organisational practices are a significant predictor of safety climate (H1) & 0.527 & 0.970 \\
\hline Aggregate perceptions of supervisory support are a significant predictor of safety climate $(\mathrm{H} 2)$ & 0.637 & 0.268 \\
\hline Aggregate perceptions of work attributes that are meaningful and empowering are a significant predictor of safety climate $(\mathrm{H} 3)$ & 0.565 & - \\
\hline $\begin{array}{l}\text { The ability of frontline supervisors to hold employees and themselves accountable has a positive influence on safety behaviour of } \\
\text { employees }(\mathrm{H} 4)\end{array}$ & 0.377 & 0.167 \\
\hline Aggregate perceptions of organisational practices are a significant predictor of supervisory accountability (H5) & 0.554 & 0.334 \\
\hline $\begin{array}{l}\text { Aggregate perceptions of work attributes that are meaningful and empowering are a significant predictor of supervisory } \\
\text { accountability (H7) }\end{array}$ & - & - \\
\hline Aggregate frontline supervisor perceptions of engagement are significantly related to safety behaviour (H8) & 0.325 & 0.242 \\
\hline $\begin{array}{l}\text { Aggregate frontline supervisor perceptions of organisational practices are a significant predictor of supervisory } \\
\text { engagement (H9) }\end{array}$ & 0.347 & - \\
\hline Aggregate frontline supervisor perceptions of supervisory support are a significant predictor of supervisory engagement $(\mathrm{H} 10)$ & 0.473 & - \\
\hline $\begin{array}{l}\text { Aggregate frontline supervisor perceptions of supervisory support are a significant predictor of supervisory } \\
\text { engagement }(\mathrm{H} 11)\end{array}$ & 0.552 & - \\
\hline
\end{tabular}


climate when keeping all other independent variables stable, with a relative 0.970 improvement in safety climate for every movement in organisational practices.

\section{Aggregate perceptions of supervisory support are a significant predictor of safety climate (H2)}

Hypothesis 2 aimed to establish whether perceptions of supervisory support could be used to predict the safety climate of an organisation. The analysis illustrated a positive, moderately strong to strong relationship between supervisory support and safety climate. Examples of supervisory support included active interest in growth and development; care and respect; encouragement for a fair, inclusive and diverse environment and useful communication. This result indicates that supervisory support that positively enhances perceptions of their organisation also positively influences the safety climate of the organisation. An analysis of variance suggests that supervisory support is the strongest predictor of safety climate when considering the organisational culture factors analysed.

\section{Aggregate perceptions of work attributes are a significant predictor of safety climate (H3)}

A moderately strong relationship between work attributes and supervisory support was found to exist. Examples of work attributes included personal accomplishment, autonomy to make decisions, transparent communication and feedback and the proper use of skills and abilities. This result indicates that work attributes that positively enhance perceptions of their organisation also positively influence the safety climate of the organisation. However, an analysis of variance indicated that work attributes were not significantly correlated with safety climate when keeping all other independent variables stable, with a relative 0.01 improvement in safety climate for every movement in work attributes. This result suggests that work attributes are an inadequate predictor of an organisation's safety climate, despite a positive correlation between the two variables.

An organisational culture that encourages safety is necessary for resilient safety performance. Although organisational practices and supportive supervisory routines can provide an effective safety framework, it is ultimately the employee's perception of the importance of safety to the organisation that governs safety behaviour. These results contribute to literature on safety by confirming that for resilient safety behaviour, an organisation requires both safety systems and an organisational culture that can support those systems.

\section{Safety behaviour}

A further objective of the research was to determine the strength and direction of the relationship between safety climate and safety behaviour. Although significant research has been undertaken to understand job performance as a dimension of safety performance, far less research has been conducted to determine how safety behaviour affects the number of incidents and accidents in the workplace (Neal \&
Griffin, 2006; Yang et al., 2019) or the impact of safety climate on individual safety behaviour. Research has shown that safety climate is an important predictor of safety behaviour and safety outcomes such as accidents and injury (Neal \& Griffin, 2006; Yang et al., 2019). This information is important as it empowers organisations with the ability to target specific interventions related to an individual's compliance with motivation to participate and participation in organisational safety practices to improve safety performance.

The three independent variables of safety climate, supervisory accountability and supervisory engagement were considered as factors of safety behaviour and were analysed for variance. Based on the adjusted $r^{2}$-value, $38.4 \%$ of the variance in safety behaviour could be attributed to climate and supervisory routines. Considering the range of other factors not considered in this research, $38.4 \%$ variance was considered significant, and thus a strong factor that organisational leadership should consider leveraging to create a positive and resilient safety climate.

\section{Aggregate perceptions of safety climate are significantly related to supervisory safety behaviour (H4)}

This hypothesis aimed to establish whether perceptions of safety climate could be used to predict the safety behaviour within the organisation. An analysis of variance indicated a significant correlation between safety climate and safety behaviour. These results are consistent with literature (Christian, Bradley, Wallace, \& Burke, 2009; Neal \& Griffin, 2006; Yang et al., 2019) although the strength of the relationship is less robust and suggests that possible extrinsic factors such as supervisory accountability or engagement may be more important determinants of changes in safety behaviour. This complements research suggesting a positive and resilient relationship between a supervisor's behaviours and safety performance (Barling, Loughlin, \& Kelloway, 2002; Conchie \& Donald, 2009; Conchie, Taylor, \& Donald, 2012; Kelloway, Mullen, \& Francis, 2006; Mullen \& Kelloway, 2009; Törner \& Pousette, 2009). Moreover, these results further motivate the critical and direct influence that frontline supervisors have on the safety behaviour within their teams (Fang et al., 2015; Lingard et al., 2012).

\section{Supervisory accountability}

Accountability is a central component in all organisations, societies and communities; without it there would be no regard for the consequences imposed by others (Hall et al., 2017; Hochwarter et al., 2007). A further objective of the research was therefore to understand how accountability for safety compliance influences safety behaviour.

The ability of frontline supervisors to hold employees and themselves accountable has a positive influence on their safety behaviour (H5)

Can supervisory perceptions of accountability be used to predict the safety behaviour of supervisory employees? The analysis showed a positive, moderately strong relationship 
between supervisory accountability and safety behaviour. The analysis of variance indicated a significant correlation between supervisory accountability and safety behaviour when keeping all other independent variables stable. This result suggests that supervisory accountability is the strongest predictor of a supervisor's safety behaviour, confirming that accountability has implications for all levels within an organisation or society (Frink \& Klimoski, 1998; Hall et al., 2017; Hochwarter et al., 2007).

\section{Aggregate perceptions of organisational practices are a significant predictor of supervisory accountability (H6)}

No significant correlation was found between the variables of supervisory accountability and organisational practices. This finding is aligned with antecedents to the accountability model developed by Pearson and Sutherland (2017), which did not find the meaning of work to be a factor considered in understanding an employee's tendency to experience or exercise accountability. This finding adds to literature on accountability by suggesting that interventions based on improving an employee's perception of the attributes of their work will not influence their tendency to be accountable for their performance, or more specifically, practise positive safety behaviours.

\section{Aggregate perceptions of supervisory support are a} significant predictor of supervisory accountability (H7)

Can perceptions of supervisory support be used to predict supervisory accountability? The analysis illustrated no significant relationship between supervisory accountability and supervisory support. This finding suggests that interventions based on improving a supervisor's tendency to value, care for, respect and grow her team neither increase her tendency to exercise accountability, nor would it encourage a greater sense of perceived accountability.

\section{Aggregate perceptions of work attributes that are meaningful and empowering are a significant predictor of supervisory accountability (H8)}

A multiple linear regression analysis between work attributes and supervisory accountability illustrated a positive, moderate relationship. This result indicates that work attributes can positively influence supervisory accountability, which will in turn have an impact on safety behaviour. An analysis of variance indicated a significant correlation between supervisory accountability and the work attributes of an organisational culture. This result also suggests that work attributes is the only predictor of supervisory accountability within the model for organisational culture considered.

\section{Supervisory engagement}

Safety engagement is defined as an employee's inclination to exert extra effort to behave in a safe manner and the extent to which employees are enthusiastic about enacting safety behaviours (Neal \& Griffin, 2006). Despite the continuing interest in supervisory safety behaviours, there has been relatively little research on factors that influence supervisors' engagement in their role of safety leadership. These results contribute to this field of research by describing the strength and direction of the relationship between supervisory engagement and safety behaviours and by providing a quantification of influential relationships between organisational culture factors and supervisory engagement to improve safety behaviours.

\section{Aggregate frontline supervisor perceptions of engagement are a significant predictor of safety behaviour (H9)}

Hypothesis 9 aimed to establish whether supervisory engagement could be used to predict safety behaviour within an organisation. The analysis illustrated a positive, moderate relationship between supervisory engagement and safety behaviour. Examples of supervisory engagement included the vigour, dedication and motivation with which supervisors approached their work. This result indicates that higher levels of supervisory engagement positively influence safety behaviour within an organisation. However, an analysis of variance did not reveal a significant correlation between supervisory engagement and safety behaviour. This result suggests that supervisory engagement is an inadequate predictor of an organisation's safety behaviour despite a positive correlation between the two variables. These outcomes contribute to literature on engagement, which has drawn a connection between higher levels of engagement and improved job performance. Extrapolating this performance to safety behaviour, however, does not produce the same result and interventions related to improving engagement do not positively influence safety behaviour.

An objective of the research was to investigate the relationship between factors of organisational culture and supervisory engagement. The three independent variables of organisational practices, supervisory support and work attributes were considered as factors of organisational culture and were analysed for variance with supervisory engagement as the dependent variable. Based on the adjusted $r^{2}$ value, 37.2\% of the variance in supervisory engagement can be attributed to organisational culture. Considering the range of other organisational culture factors not considered in this research, a $37.3 \%$ variance was considered significant, and thus a strong factor that organisational leadership should consider leveraging to create a more engaged supervisory workforce. Sahoo and Mishra (2012) identified career development, communication, empowerment, fair treatment and equal opportunities, cooperation, constructive performance feedback, salary and benefits, image, health and safety and overall employee wellbeing as being key drivers of employee engagement. These constructs were all included in the model for organisational culture. It is therefore unsurprising that the results confirm Sahoo and Mishra's (2012) findings.

\section{Aggregate frontline supervisor perceptions of organisational practices are a significant predictor of supervisory engagement (H10)}

Can perceptions of organisational practices be used to predict the supervisory engagement levels within an organisation? 
The multiple linear regression analysis between organisational practices and supervisory engagement illustrated a positive, moderate relationship. However, an analysis of variance indicated no significant correlation between supervisory engagement and organisational practices when keeping all other independent variables stable, and thus organisational practices cannot be considered to accurately predict the level of supervisory engagement. This finding directly contradicts Schneider et al. (2018), who found that organisational practices were the strongest correlate for workforce engagement. Given that this research was conducted on only one organisation, it may not be that organisational practices are not significant predictors of supervisory engagement, but perhaps that these practices are not tangible enough for employees at the organisation in question, leading to an insignificant influence on supervisory engagement (Schneider et al., 2018).

\section{Aggregate frontline supervisor perceptions of supervisory support are a significant predictor of supervisory engagement (H11)}

Can perceptions of supervisory support be used to predict the supervisory engagement levels within the organisation? The analysis illustrated a positive, moderately strong relationship between supervisory engagement and supervisory support. An analysis of variance indicated a significant correlation between supervisory engagement and levels of supervisory support when keeping all other independent variables stable and thus can be seen to accurately predict the level of supervisory engagement. This finding agrees with Schneider et al. (2018), who found supervisory support to be strongly correlating with workforce engagement.

\section{Aggregate frontline supervisor perceptions of work attributes that are meaningful and empowering are a significant predictor of supervisory engagement (H12)}

Can perceptions of work attributes be used to predict supervisory engagement levels within the organisation? The correlation between work attributes and supervisory support illustrated a positive, moderately strong relationship. The analysis of variance indicated a significant correlation between supervisory engagement and the levels of work attributes in an organisational culture when keeping all other independent variables stable and thus can be seen to accurately predict the level of supervisory engagement. This result also suggests that work attributes are the strongest predictor of supervisory engagement within the model for organisational culture considered.

In summary, after presenting the descriptive statistics and demographic profile for the sample, the results of a CFA were presented to prove the reliability and validity of the underlying structure. The validated model was used to test the identified hypotheses using multiple regression analysis to determine the nature - strength, direction and significance - of the relationship between the independent and dependent variables. Of the 12 hypotheses proposed, 5 were rejected because the independent variable was not a statistically significant predictor of the dependent

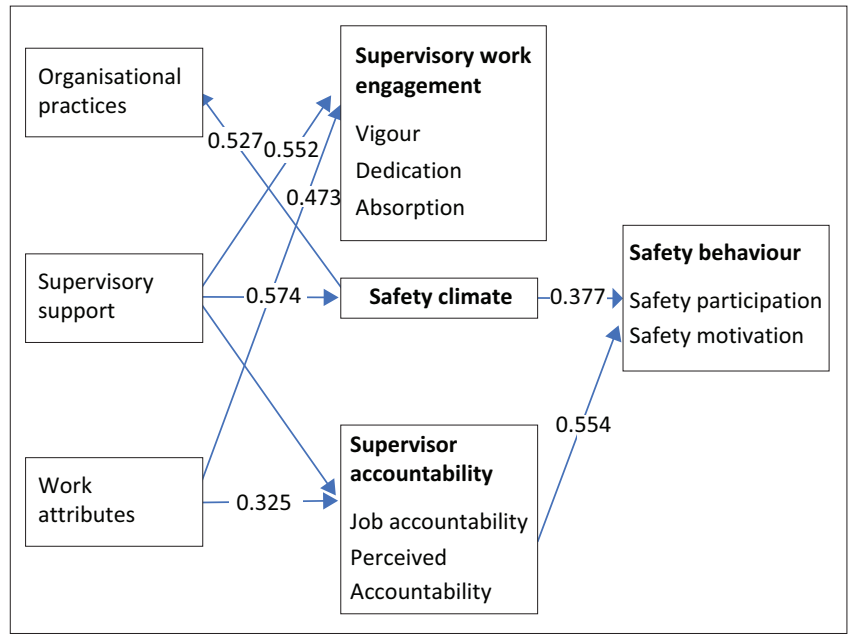

FIGURE 1: Proposed model using validated factor structure and indicating hypotheses with associated correlation coefficients.

variable. The validated model, updated with only accepted hypotheses and their correlation coefficients, is shown in Figure 1.

\section{Discussion Outline of the results}

The results indicate that the tendency of a supervisor to hold herself, and her team accountable is positively correlated with good safety behaviour and is the strongest predictor of safety behaviour when considering safety climate, supervisory engagement and supervisory accountability, adding new data to the body of knowledge on accountability (Pearson \& Sutherland, 2017). Despite significant positive correlations existing between supervisory engagement, safety climate and safety behaviour, of the two independent variables, only safety climate was found to be a significant predictor of safety behaviour. These results are aligned with findings by Hofmann and Morgeson (1999), Fang et al. (2015); Lingard et al. (2012), Delbridge and Lowe (1997) and Weick et al. (1997) and indicated that to improve safety behaviour, mining leaders need to focus on capacitating and empowering supervisors to hold their teams accountable and be accountable themselves. This should be followed by initiatives to improve the safety climate.

Safety climate was found to be a significant contributor to safety behaviour. All three organisational culture factors organisational practices, supervisory support and work attributes - were found to be strong predictors, indicating a significant influence between organisational culture and safety climate and adding to the body of knowledge describing culture and climate (Zohar \& Luria, 2003). To increase safety climate, and subsequent safety behaviour, leaders should focus on leveraging these characteristics to effect safety performance.

The only significant organisational culture factor predictor for supervisory accountability was found to be work attributes, further adding to the body of knowledge (Pearson \& Sutherland, 2017). Organisational practices and 
supervisory support were not found to contribute to supervisory accountability. The strongest organisational culture factor predictor of safety climate was supervisory support, and this is important new knowledge, and previously no link between supervisory support and safety climate has been available. It thus seems prudent for organisational leaders to focus their efforts on increasing supervisory support behaviours and the work attributes of supervisors. Such a focus is likely to result in the greatest indirect increase in safety behaviour and subsequent safety performance.

Although supervisory engagement was found to positively correlate with safety behaviour, it was not found to be a strong or significant predictor. These findings are aligned with Sahoo and Mishra (2012) and efforts to increase the engagement levels of supervisors would not go amiss, but the contribution of these efforts to safety behaviour and subsequent safety performance would not likely be substantial in the short to medium term. Should initiatives be undertaken to increase supervisory engagement, the organisational culture factors that will produce the most significant contributions are, again, supervisory support and work attributes.

\section{Practical implications}

The study indicates opportunities for platinum mine leadership and those responsible for employee health and safety at mines to tie together supervisory behaviour and organisational culture tools to address safety behaviour and performance. By creating a robust safety climate, mine leadership may not be addressing the inherent safety hazards associated with mining, but rather, they would be focussing on the human behaviour, attitudes and reactions to the work environment.

The results of this study indicate that some of the traditional understanding of supervisory engagement and its positive effect on organisational performance may not be accurately extrapolated to influence safety behaviour. However, increasing supervisory accountability and safety climate by leveraging organisational culture is becoming more and more apparent in the quest to develop robust safety behavioural patterns amongst frontline employees in the platinum mining environment. Whilst it is important for frontline supervisors and managers to acknowledge the important role they play in enforcing accountability within their teams, it is also imperative for them to recognise other organisational influences - such as supervisory support, work attributes and organisational practices - that affect safety behaviour. This is of importance given that positive safety behaviour impacts the number of injuries and incidents experienced on the mine.

While the factor-based model derived was somewhat complex, the strong relationships between organisational culture and safety climate and behaviour, as well as supervisory accountability and safety behaviour create several opportunities for managers and business to analyse.

The research specifically identified the strong and positive relationship between supervisory accountability and safety behaviour whilst identifying work attributes as the strongest organisational culture factor in trying to influence supervisory accountability. Managers should thus ensure that frontline supervisors are equipped to act within an accountability framework and that all employees experience this accountability consistently:

- Supervisors should take the time to understand the organisational culture of the workplace to promote the development of positive safety behaviour amongst their teams. This includes building social capital with their teams that can be interpreted as supervisory support, in promotion of the organisational vision, purpose and values of the firm.

- When administering a formal accountability framework, supervisors should use a combination of positive reinforcement and support systems that contribute to a better understanding of the work attributes and how these influence organisational effectiveness. Consideration should be given to recognising positive safety behaviour through leading indicators as much as identifying detrimental safety behaviours. In addition, accountability in the form of rewards and recognition, incentives and remuneration can be used to create effective work management systems.

- Of critical importance is the promotion and hiring of frontline supervisors. Managers should ensure that the correct type of employee is promoted or hired into frontline supervisory positions. These employees should have a strong personal tendency to hold themselves and others accountable for poor safety performance and nondelivery and their personal values and ethical conduct should be strongly aligned with the organisational culture. Developing a custom-made recruitment and selection process to ensure compliance with the culture will be helpful, as well as intentional training and development programmes, which capacitate and support frontline supervisors to act on the accountability framework of the organisation.

- Frontline supervisors should put the required effort to ensure that the role or task attributed to an employee is well articulated and understood using simple and clear communication, instructions, performance measurement and consequence management. By eliminating ambiguity and by ensuring employees are adequately versed in the attributes of their task, individuals cannot claim that they did not know or understand and thus cannot be held accountable.

- The study also highlights the critical importance of an effective and well functionary frontline supervisory workforce. Effective supervisors apply themselves not only physically, but cognitively and emotionally too, and given their proximity to the workforce, inadequate engagement or ineffective supervisory behaviours will 
inhibit how successfully an organisation's strategy is operationalised.

- The hierarchical nature of mining organisations within South Africa allows for safety interventions at the supervisory level, just above the level where most workplace injuries occur. By introducing better integrated training and supervisory behaviour modification programmes, it is expected that the benefits will be greater than worker targeted programmes.

- An important aspect of effective supervision is the ability to juggle multiple and competing priorities. Interventions that focus on providing regular feedback on performance, specifically safety behaviour and safety-related decision making, will allow for supervisors to change their safety supervisory practices and improve perceptions of safety climate and behaviour.

- For business leadership, it will be important that adequate investment is made in training and development of supervision. Organisational practices such as performance management, regular feedback and communication, fair and transparent succession planning, reward and recognition programmes were found to be strongly correlated with an improved supervisory safety climate. Targeted interventions that capacitate supervisors with this knowledge and ability will allow for positive safety behavioural changes.

- Work attributes, or characteristics, such as compensation and the nature of the work itself were found to strongly influence the tendency of the supervisor to exhibit accountable behaviour. Mining working conditions are far from ideal and involve difficult, harsh and uncomfortable conditions that can negatively affect the perception of work attributes associated with mining supervision. Business leadership will need to develop intentional strategies to combat these negative mediating effects on perceptions of work characteristics if supervisory accountability is to be prioritised and used to improve safety behaviours.

\section{Limitations and recommendations}

The research was limited to a single organisation within the platinum mining industry, and thus, the findings may not be applicable to other organisations or indeed the rest of the industry. Furthermore, a second limitation of the research methodology was the sample size. Despite the total population being small, a sample size of just more than 100 is lower than ideal for completing confirmatory analysis and drawing statistical conclusions. Furthermore, the population consisted of individuals whose home language may not be English and whose level of education might be limited. These factors might limit the findings of the research because of interpretation of certain constructs.

The study was conducted as a static, cross-sectional survey, and as such, the results are limited to a static, one point in time view. This implies that responses to the constructs may be dependent on the mood of the participant. A supervisor who had just been held accountable by her manager may see the organisational culture more negatively than if she had experienced a more positive interaction.

The research methodology employed was quantitative in nature and this is limited. The use of Likert scale responses limits the amount of detail included, and as a result, it is improbable that sufficient data will be collected to offer explanatory answers to all the associations identified. Furthermore, the survey was long, and it was observed that respondents were fatigued by the time it was over, possibly resulting in a rush to finish the survey.

The population consisted of individuals whose home language might not be English and whose level of education might be limited. These factors might limit the findings of the research because of interpretation of certain constructs.

\section{Conclusion}

Literature confirms that supervision in the mining industry is critical to managing safety behaviour and performance. Furthermore, literature affirms the importance of supervisory behaviours such as accountability and engagement in organisational performance. Despite this, very little evidence exists as to how these supervisory behaviours impact safety performance within the mining industry, and how organisational culture factors influence these supervisory tendencies. This research attempted to close this gap in literature and the framework, which emerged provides a clear understanding as to which aspects of supervisory behaviour have the biggest impact on safety behaviour and which organisational factors could be used to modify supervisory behaviour most effectively in order to improve safety performance.

This research contributes to literature by providing empirical evidence and key insights into the complexity of safety behaviour in the mining industry. Furthermore, it is suggested that the research contributes to the practice of business leadership and management in providing a framework, which can be utilised by consultants, managers and supervisors looking to prioritise factors by level of impact to drive improved safety behaviours and organisational performance.

\section{Acknowledgements Competing interests}

The authors declared that no competing interest exists.

\section{Authors' contributions}

The research was undertaken by H.P. The first draft of the article was written by H.P. K.B.H. supervised the research and co-wrote the article and prepared it for submission. 


\section{Funding information}

This research received no specific grant from any funding agency in the public, commercial, or not-for-profit sectors.

\section{Data availability}

Data sharing is not applicable to this article as no new data were created or analysed in this study.

\section{Disclaimer}

The views and opinions expressed in this article are those of the authors and do not necessarily reflect the official policy or position of any affiliated agency of the author

\section{References}

Al Mazrouei, M.A., Khalid, K., Davidson, R., \& Abdallah, S. (2019). Impact of organizational culture and perceived process safety in the UAE oil and gas industry. The Qualitative Report, 24(12), 3215-3238. https://doi. org/10.46743/2160-3715/2019.3971

Barbars, A. (2015). Interaction between organisational culture and work engagement in an IT department within a financial. Journal of Business Management, 10 (1691-5348), 106-148.

Barling, J., Loughlin, C., \& Kelloway, E.K. (2002). Development and test of a model linking safety-specific transformational leadership and occupational safety. Journal of Applied Psychology, 87(3), 488-496. https://doi.org/10.1037/0021 9010.87.3.488

Brown, S.P., \& Leigh, T.W. (1996). A new look at psychological climate and its relationship to job involvement, effort, and performance. Journal of Applied Psychology, 81(4), 358-368. https://doi.org/10.1037/0021-9010.81.4.358

Cao, L., \& Ramesh, B. (2008). Agile requirements engineering practices: An empirical study. IEEE Software, 25(1), 60-67. https://doi.org/10.1109/MS.2008.1

Cardus, M. (2013). The five levers of employee engagement. The Journal for Quality and Participation, 36(2), 28-31.

Chen, C.H., \& Chiu, C.H. (2016). Employing intergroup competition in multitouch design-based learning to foster student engagement, learning achievement, and creativity. Computers \& Education, 103, 99-113. https://doi.org/10.1016/j. compedu.2016.09.007

Christian, M.S., Bradley, J.C., Wallace, J.C., \& Burke, M.J. (2009). Workplace safety: A meta-analysis of the roles of person and situation factors. Journal of Applied Psychology, 94(5), 1103-1127. https://doi.org/10.1037/a0016172

Conchie, S.M., \& Donald, I.J. (2009). The moderating role of safety-specific trust in the relation between safety-specific leadership and safety citizenship behaviors. Journal of Occupational Health Psychology, 14(2), 137-147. https://doi org/10.1037/a0014247

Conchie, S.M., Taylor, P.J., \& Donald, I.J. (2012). Promoting safety voice through safetyspecific transformational leadership: The mediator roles of two dimensions of trust. Journal of Occupational Health Psychology, 17(1), 105-115. https://doi org/10.1037/a0025101

Cummings, G.G., MacGregor, T., Davey, M., Lee, H., Wong, C.A., Lo, E., ... Stafford, E. (2010). Leadership styles and outcome patterns for the nursing workforce and work environment: A systematic review. International Journal of Nursing Studies, 47(3), 363-385. https://doi.org/10.1016/j.ijnurstu.2009.08.006

Delbridge, R., \& Lowe, J. (1997). Manufacturing control: Supervisory systems on the new shop floor. Sociology, 31(3), 409-426. https://doi.org/10.1177/00380 38597031003003

Department of Minerals and Resources (2020). Statement on the release of the 2019 mine health and safety statistics, https://www.dmr.gov.za/news-room/post/1839/ statement-on-therelease-of-the-2019-mine-health-and-safety-statistics-24january-2020

Dingsdag, D.P., Biggs, H.C., \& Sheahan, V.L. (2008). Understanding and defining OH\&S competency for construction site positions: worker perceptions, Safety Science, 46/2008, 619-633.

Fang, D., Wu, C., \& Wu, H. (2015). Impact of the supervisor on worker safety behaviour in construction projects. Journal of Management in Engineering, 31(6), 04015001. https://doi.org/10.1061/(ASCE)ME.1943-5479.0000355

Fairlie, P. (2011). Meaningful work, employee engagement, and other key employee outcomes: Implications for human resource development. Advances in Developing Human Resources, 13(4), 508-525. https://doi.org/10.1177/152342 2311431679

Frink, D.D., \& Klimoski, R.J. (1998). Toward a theory of accountability in organizations and human resources management. In G.R. Ferris (Ed.), Research in personnel and human resources management (Vol. 16, pp. 1-50). Greenwich, CT: JAI Press.

Hakanen, J.J., Schaufeli, W.B., \& Ahola, K. (2008). The job demands-resources model: A three-year cross-lagged study of burnout, depression, commitment, and work engagement. Work \& Stress: An International Journal of Work, Health \& Organisations, 22(3), 224-241. https://doi.org/10.1080/02678370802379432
Hall, A.T., Frink, D.D., \& Buckley, M.R. (2017). An accountability account: A review and synthesis of the theoretical and empirical research on felt accountability. Journal of Organizational Behavior, 38(2), 204-224. https://doi.org/10.1002/job.2052

Hewitt, A. (2012). 2012 trends in global employee engagement (p. 18). Chicago: Aon Hewitt Corp.

Hochwarter, W.A., Ferris, G.R., Gavin, M.B., Perrewé, P.L., Hall, A.T., \& Frink, D.D. (2007). Political skill as neutralizer of felt accountability - Job tension effects on job performance ratings: A longitudinal investigation. Organizational Behavio and Human Decision Processes, 102(2), 226-239. https://doi.org/10.1016/j. obhdp.2006.09.003

Hochwarter, W.A., Kacmar, C.J., \& Ferris, G.R. (2003). Accountability at work: An examination of antecedents and consequences. Paper presented at the annual meeting of the Society of Industrial and Organizational Psychology, Orlando, FL.

Hofmann, D.A., \& Morgeson, F.P. (1999). Safety-related behavior as a social exchange: The role of perceived organizational support and leader-member exchange. Journal of Applied Psychology, 84(2), 286-296. https://doi.org/10.1037/0021-9010.84.2.286

Kelloway, E.K., Mullen, J., \& Francis, L. (2006). Divergent effects of transformational and passive leadership on employee safety. Journal of Occupational Health Psychology, 11(1), 76-86. https://doi.org/10.1037/1076-8998.11.1.76

Kunda, R., Frantz, J., \& Karachi, F. (2013). Prevalence and ergonomic risk factors of work-related musculoskeletal injuries amongst underground mine workers in Zambia. Journal of Occupational Health, 55(3), 211-217. https://doi.org/10.1539/ joh.11-0175-FS

Lee, T., \& Harrison, K. (2000). Assessing safety culture in nuclear power stations. Safety Science, 34(1-3), 61-97. https://doi.org/10.1016/S0925-7535(00)00007-2

Lingard, H., Cooke, T., \& Blismas, N. (2011). Coworkers' response to occupational health and safety: An overlooked dimension of group-level safety climate in the construction industry? Engineering, Construction and Architectural Management, 18(2), 159-175. https://doi.org/10.1108/09699981111111139

McCall, J.R., \& Pruchnicki, S. (2017). Just culture: A case study of accountability relationship boundaries influence on safety in HIGH-consequence industries. Safety Science, 94, 143-151. https://doi.org/10.1016/j.ssci.2017.01.008

Michael, J.H., Guo, Z.G., Wiedenbeck, J.K., \& Ray, C.D. (2006). Production supervisor impacts on subordinates' safety outcomes: An investigation of leader-member exchange and safety communication. Journal of Safety Research, 37(5), 469-477. https://doi.org/10.1016/j.jsr.2006.06.004

Minerals Council South Africa. (2020). Minerals council president on 'the state of the mining nation' and publication of facts and figures pocketbook 2020. Retrieved from https://www.mineralscouncil.org.za/special-features/1201-the-state-ofthe-mining-nation

Morrison, D.L., Upton, D.M., \& Cordery, J. (1997). Organizational Climate and Skill Utilization. Paper presented to the 12th Annual Conference of the Society for Industrial and Organizational Psychology. April 1997. St. Louis, MI.

Mullen, J., \& Kelloway, E.K. (2009). Safety leadership: A longitudinal study of the effects of transformational leadership on safety outcomes. Journal of Occupational and Organisational Psychology, 82(2), 253-272. https://doi. org/10.1348/096317908X325313

Muthuveloo, R., Basbous, O.K., Ping, T.A., \& Long, C.S. (2013). Antecedents of employee engagement in the manufacturing sector. American Journal of Applied employee engagement in the manufacturing sector. American Journal of $A$
Sciences, 10(12), 1546. https://doi.org/10.3844/ajassp.2013.1546.1552

Neal, A., Griffin, M.A., \& Hart, P.M. (2000). The impact of organizational climate on safety climate and individual behavior. Safety science, 34(1-3), 99-109.

Neal, A., \& Griffin, M.A. (2006). A study of the lagged relationships among safety climate, safety motivation, safety behaviour, and accidents at the individual and group levels. Journal of Applied Psychology, 91(4), 946. https://doi. org/10.1037/0021-9010.91.4.946

Pearson, H., \& Sutherland, M. (2017). The complexity of the antecedents influencing accountability in organisations. European Business Review, 29(4), 419-439. https://doi.org/10.1108/EBR-08-2016-0106

Pousette, A., Larsson, S., \& Törner, M. (2008). Safety climate cross-validation, strength and prediction of safety behaviour. Safety Science, 46(3), 398-404. https://doi org $/ 10.1016 /$ j.ssci.2007.06.016

Sahoo, C.K., \& Mishra, S. (2012). A framework towards employee engagement: The PSU experience. ASCI Journal of Management, 42(1), 92-110.

Saunders, M., Lewis, P.H.I.L.I.P., \& Thornhill, A.D.R.I.A.N. (2007). Research methods. England: Business Students 4th edition Pearson Education Limited.

Saunders, M.N., \& Lewis, P. (2018). Doing research in business \& management: An essential guide to planning your project. Pearson.

Schaufeli, W.B., Martínez, I., Marques-Pinto, A., Salanova, M., \& Bakker, A.B. (2002). Burnout and engagement in university students: A cross national study. Journal of Cross-Cultural Psychology, 33(5), 464-481. https://doi. org/10.1177/0022022102033005003

Schneider, B., Yost, A.B., Kropp, A., Kind, C., \& Lam, H. (2018). Workforce engagement: What it is, what drives it, and why it matters for organizational performance. Journal of Organizational Behavior, 39(4), 462-480. https://doi.org/10.1002/job.2244

Stemn, E., Bofinger, C., Cliff, D., \& Hassall, M.E. (2019). Examining the relationship between safety culture maturity and safety performance of the mining industry. Safety Science, 113, 345-355. https://doi.org/10.1016/j.ssci.2018.12.008

Subrahmanian, M. (2014). Drivers of employee engagement in petroleum industry-A transformational framework. Journal of Human Resource Management, 24(14), 2741-2759

Tholén, S.L., Pousette, A., \& Törner, M. (2013). Causal relations between psychosocial conditions, safety climate and safety behaviour - A multi-level investigation. Safety Science, 55, 62-69. https://doi.org/10.1016/j.ssci.2012.12.013 
Törner, M., \& Pousette, A. (2009) Safety in construction - A comprehensive description of the characteristics of high safety standards in construction work, form the Research, 40(6), 399-409. https://doi.org/10.1016/j.jsr.2009.09.005

Weick, K.E., Sutcliffe, K.M., \& Obstfeld, D. (1997). Organizing for high reliability: The mindful suppression of inertia. Michigan: University of Michigan, Business School, Research Support.

Wiegmann, D.A., Zhang, H., Von Thaden, T.L., Sharma, G., \& Gibbons, A.M. (2004). Safety culture: An integrative review. The International Journal of Aviation Psychology, 14(2), $117-134$
Yang, L.Q., Zheng, X., Liu, X., Lu, C.Q., \& Schaubroeck, J.M. (2019). Abusive supervision, thwarted belongingness, and workplace safety: A group engagement perspective. thwarted belongingess, and workplace safety. A group engagement perspective. apl0000436

Zohar, D. (2010). Thirty years of safety climate research: Reflections and future directions. Accident Analysis and Prevention, 42(5), 1517-1522. https://doi. org/10.1016/j.aap.2009.12.019

Zohar, D., \& Luria, G. (2003). The use of supervisory practices as leverage to improve safety behaviour: A cross level intervention model. Journal of Safety Research, 34(5), 567-577. https://doi.org/10.1016/j.jsr.2003.05.006 